\title{
Optimization of Capillary Tube Parameters in Vapour Compression System using Environmentally Friendly Refrigerant R1234yf
}

\author{
Gaurav $^{\# 1}$, Raj Kumar*2 \\ ${ }^{1 *}$ Research Scholar, Department of Mechanical Engineering, YMCA University of Science \& Technology, \\ Faridabad-121006, Haryana, India, E-mail: gaurav.citm@gmail.com \\ ${ }^{2 *}$ Department of Mechanical Engineering, YMCA University of Science \& Technology, Faridabad-121006, \\ Haryana, India
}

\begin{abstract}
The increasing concern about global warming demands a replacement of currently used refrigerant R134a, which has a global warming potential (GWP) value of 1300 . The refrigerant 2, 3, 3, 3tetrafluoropropene (HFO-1234yf or R1234yf) is identified as the new low global warming refrigerant for household refrigerator and may substitute the existing refrigerant R134a. The capillary tube parameters for R134a are well known but the investigation is required for parameters when the system is charged with R1234yf. This paper presents a comparative analysis of a vapour compression refrigeration system with refrigerants R134a and R1234yf by changing parameters of a capillary tube. The effects of capillary tube length and diameter have been analyzed for the optimum coefficient of performance (COP) in the vapour compression refrigeration system using R1234yf as a refrigerant.
\end{abstract}

Keyword- COP, Capillary, Design parameter, Alternate refrigerant.

\section{INTRODUCTION}

COP is the ratio of refrigeration effect to the net work input given to the system. Thus, COP of a system can be improved either by reducing work input given to the system or by increasing the refrigeration effect. The expansion process is one of the main factors responsible for energy loss in vapour compression cycle performance because as refrigerant enters the capillary tube it flashes to vapour and in evaporator it will reduce the cooling capacity, as a consequence the size of evaporator increases. This problem can be eliminated by adopting multi-stage expansion with the flash chamber in which the flash vapour is removed after each stage of expansion. Refrigeration effect can also be increased by passing the refrigerant through subcooler after condenser to the evaporator.

R12 refrigerant was widely used for domestic refrigeration, but it has been replaced by R134a, which is a hydrofluorocarbon (HFC) having zero ozone depletion potential (ODP). But, it has been found that refrigerant $\mathrm{R} 134 \mathrm{a}$ is one of the factors responsible for the increase in global warming throughout the world with a global warming potential (GWP) of 1300. This means that in the atmosphere, the emission of $1 \mathrm{~kg}$ of R134a is equivalent to $1300 \mathrm{~kg}$ of $\mathrm{CO}_{2}$. Besides that $\mathrm{R} 134 \mathrm{a}$ has an atmospheric lifetime of 13 years. Thus, there is a need for better alternatives which will have zero ODP and zero or lower GWP. Many investigations have been conducted in the research to find a substitute for R134a. R1234yf is a new refrigerant which has lower global warming potential than R134a. R1234yf has a global warming potential (GWP) of 4 and satisfy the MAC Directive (GWP below 150) passed in 2006. Table 1 shows the characteristics of R12 and R134a and R1234yf [1].

Table 1

Characteristic of R12, R134a and R1234f [1]

\begin{tabular}{|l|l|l|l|}
\hline Characteristics & R12 & R134a & R1234yf \\
\hline Molecular Weight & 120.92 & 102.03 & 114.04 \\
\hline Boiling Point $\left({ }^{\circ} \mathrm{C}\right)$ & -29.75 & -26.07 & -29.03 \\
\hline $\begin{array}{l}\text { Ozone Depletion Potential } \\
\text { (ODP) }\end{array}$ & 1 & 0 & 0 \\
\hline $\begin{array}{l}\text { Global Warming Potential } \\
(\text { GWP) }\end{array}$ & 8500 & 1300 & 4 \\
\hline
\end{tabular}

Saravanakumar and Selladurai [2] compared the performance of R134a and hydrocarbon mixture (R290/R600a) and found that a hydrocarbon mixture showed higher COP and energetic efficiency than R134a. 
Mani and Selladurai. [3] have analyzed a vapour compression refrigeration system (VCRS) with the new R290/R600a refrigerant mixture as a drop-in replacement and compared with R12 and R134a. The results showed that the refrigerant R290/R600a (68/32 by wt \%) mixture had the higher refrigerating capacity than R12 and R134a, and discharge temperature as well as pressure very close to R12. Thus, tested hydrocarbon mixture can be considered as a drop-in replacement refrigerant for R12 and R134a. Reaosr [4] compared the refrigerants R1234yf, R410A, R134a and through simulation, determine the feasibility of using R1234yf as a replacement for R134a and R410A. The results of the simulation showed that R134a and R1234yf have similar results for heat load and outlet refrigerant temperature; however pressure drop does vary which requires a change to heat exchanger design and piping in these systems. Mohanraj et al. [5] concluded through experimental investigation of domestic refrigerator that under different environmental temperatures, mixture of R290 and R600a (in the ratio of 45.2: 54.8 by weight) showing up to $3.6 \%$ greater COP than same system using R134a, also discharge temperature of the compressor with a mixture of R290 and R600a is lower in the range of 8.5-13.4K than same compressor with R134a. Han et al. [6] showed experimentally that ternary non-azeotropic mixture of R32/R125/R161 has pressure ratio and power consumption, lower than those of R407C but the refrigeration capacity and COP are superior to those of R407C. Thus, it can be used as an alternative to R407C. Li et al. [7] have investigated that R1234yf has been proposed for mobile air-conditioners because of its low GWP and performance comparable to that of R134a, but still it is difficult to be applied to residential air-conditioners because its performance is inferior to that of R410a. In order to apply the low-GWP refrigerant to residential airconditioners, refrigerant mixtures of R1234yf and R2 at two mass fractions (80/20 and 50/50 by mass\%) are proposed and their flow boiling heat transfer performances were investigated in a smooth horizontal tube with an inner diameter of $2 \mathrm{~mm}$. The results showed that the values heat transfer coefficients for the mixture (with the R32 mass fraction of 20\%) were $10-30 \%$ less than those of refrigerant R1234yf. When the mass fraction of R32 increased to $50 \%$ in the mixture, the value of heat transfer coefficients were $10-20 \%$ greater than those of pure R1234yf under conditions of large mass and heat fluxes. However, in comparison to pure R32, the values of heat transfer coefficients of the mixtures were about $20-50 \%$ lesser. Agrawal et al. [8] illustrated a model for calculating thermodynamic properties of refrigerant R-1234yf using three different cubic equations of state, i.e. Peng-Robinson, $\mathrm{Yu}-\mathrm{Lu}$ and Guo-Du. A generic technique applicable to any fluid based on the concept of departure functions was employed. The NIST-REFPROP database is used to validate the thermodynamic properties generated using each cubic equation. It was concluded that Pen-Robinson (PR) model is simpler and computationally less expensive for determining thermodynamic properties of R1234yf. Ooi [9] examined the detailed effects of existing compressor performance on R1234yf which was originally designed for R134a. Secondly, a new compressor to be designed for R1234yf also discussed from the design point of view. In the paper, the rolling piston compressor was used to carry out the simulation tests. The detailed comparison of various performance parameters for the compressor was discussed. Jain and Bullard [10] suggested that the capillary dimensions play an important role in the system performance. Capillary tubes with large inlet and relatively short outlet were found to give the best performance at all the tested off-design condition.

Although a lot of work can be found on refrigerants R134a and R1234yf for various thermodynamic properties and compressor performance, but very limited work on optimization of a capillary dimension such as length and diameter for refrigerant R1234yf. So, there is a need of finding capillary tube parameters when the system is charged with R1234yf. The present work is a systematic comparison of the cooling capacity, COP, capillary tube length and diameter for optimizing the refrigerating effect of R1234yf.

\section{MATERIAL AND METHOD}

The basic refrigeration and air-conditioning system consist of the evaporator, compressor, condenser and capillary tube. With no moving parts and leak proof system, the capillary tube is widely used to provide required pressure drop between the condenser and evaporator. Capillary tube also regulates the mass flow rate through the system. Selection of the capillary tube is based upon the required pressure drop, compressor specifications, mass flow rate, and cooling capacity required. 


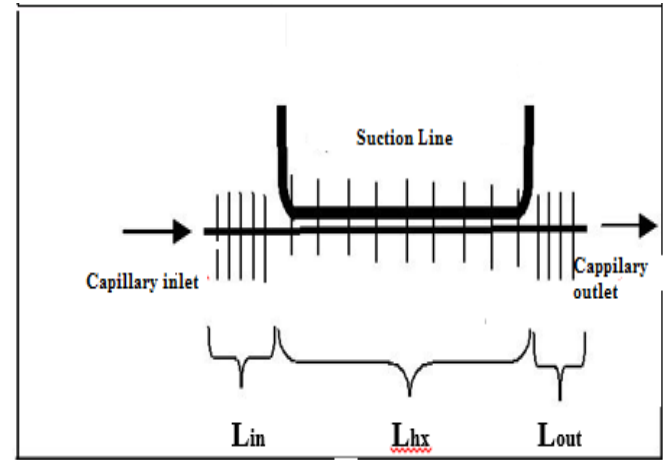

(a)

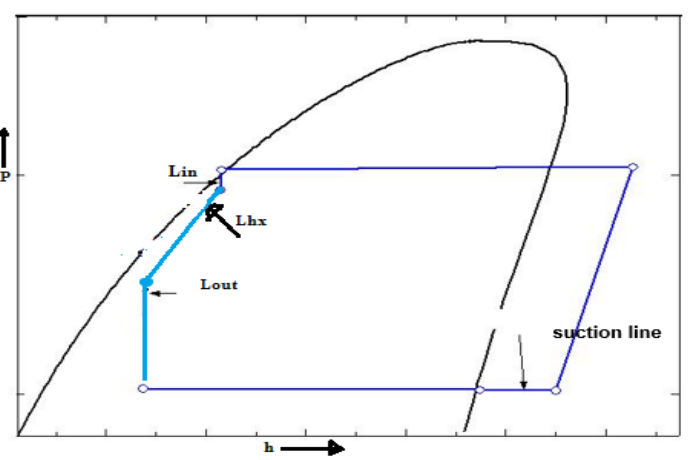

(b)

Fig. 1. a. Capillary tube length parameters b. P-h diagram

R134a vapour compression cycle efficiency benefits greatly from the suction line heat exchange. The capillary tube suction line heat exchanger in a domestic refrigerator comprises an adiabatic inlet section, a heat exchanger section and an adiabatic outlet section. The refrigerant after leaving the condenser flashes in the adiabatic inlet section and enters the heat exchanger section of the capillary tube (Fig. 1 a \& b), where it rejects heat to the cold suction line downstream of the evaporator and enters the adiabatic outlet section pressure.

The capillary dimensions play an important role in deciding its contribution to the system performance. It is important to identify what all combinations of capillary tube diameter and lengths can give a stable and efficient performance as the heat exchanger length is maximized to utilize whatever suction line length is accessible.

Specifications of compressor were: a displacement of $6.3 \mathrm{~cm}^{3}$, the rotational speed of $3000 \mathrm{rpm}$, isentropic efficiency of $70 \%, 1 / 6 \mathrm{hp}$ compressor and a mechanical efficiency of $85 \% . \mathrm{T}_{\text {amb. }}=32.2^{0} \mathrm{C}$ was recorded in the present work. The size of the capillary tube is fairly critical. Unlike orifices, the pressure drop in expansion device such as capillary tubes depends on their length as well as their diameter. The relationship between these two factors has been illustrated. Three capillary tubes of copper metal of different inner diameter $0.78 \mathrm{~mm}$, $0.81 \mathrm{~mm}$ and 0.83 and same outer diameter $2.1 \mathrm{~mm}$ were selected. A $3.600 \mathrm{~m}$ length was selected from the chart [11] and increment of $10 \%$ length was given in two stages for R1234yf. Nine observations were recorded for each refrigerant using various combinations of length and diameter. S, M, L stands for small, medium and large size. In two letters for capillary tube like SM: first letter stands for the inner diameter of the capillary tube and second letter stands for the length.

\section{EXPERIMENTAL SETUP}

Since the alternative refrigerant R1234yf has a working pressure range similar to that of the conventional R134a system and allows application of the same refrigerant oil (POE oil). A perfect vacuum was created in the system after the evaluation of R134a, and the same experiment was then repeated for the R1234yf. The validation was done on refrigeration vapour compression test rig (Fig.2). The experiments were done on the test rig for measuring cooling capacity and work input. Equipments used for measuring cooling capacity were : energy meter for evaporator heater, temperature sensor, PID glycol temperature controller, evaporator glycol tank of 40 litres with ethylene glycol 8 litres. When the test rig is operating, glycol gets cooled and an equivalent amount of heat is supplied through heaters. The heat energy supplied is equivalent to cooling capacity and is recorded by the difference in the energy meter reading.

$E_{1}$ is initial energy meter reading and $E_{2}$ is final energy meter reading, then $\left(E_{2}-E_{1}\right)$ is the difference in the energy meter reading and corresponds to cooling capacity. Work input to the compressor, was recorded by the difference in energy meter reading for achieving the cooling capacity in the evaporator consisting of glycol. $\mathrm{E}_{3}$ is initial energy meter reading for work input in the compressor and $E_{4}$ is final energy meter reading for work input in the compressor, then $\left(\mathrm{E}_{4}-\mathrm{E}_{3}\right)$ is the difference in the energy meter reading and corresponds to compressor work input. The error of the power input data was $+/-0.1 \%$ and cooling capacity measurent was $+/$ $-3 \%$. 


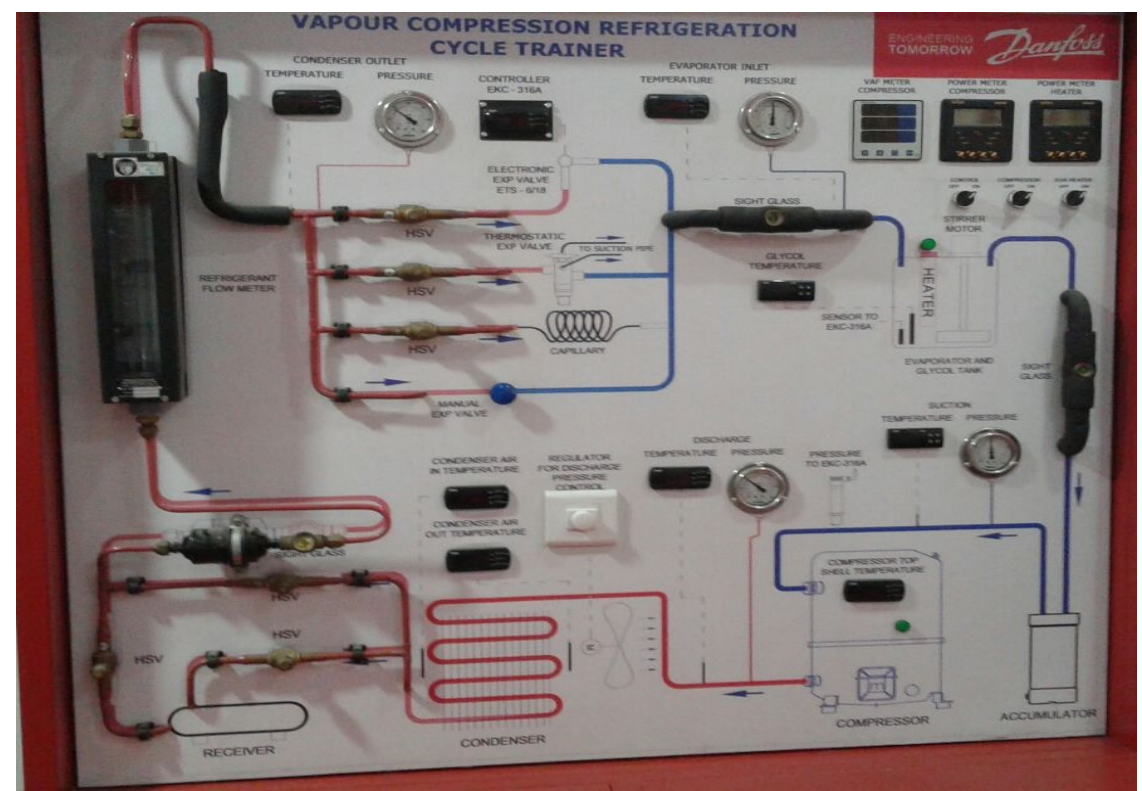

Fig. 2. Refrigeration test rig

\section{RESULT AND DISCUSSTION}

Optimum length and diameter of capillary tube were estimated through an experimental investigation by replacing R134a with R1234yf. For comparison, firstly the results were recorded using R134a (Table 2).

Table II

Effect of capillary tube size on various properties of R134a

\begin{tabular}{|l|l|l|l|l|c|}
\hline $\begin{array}{l}\text { Sr. } \\
\text { No. }\end{array}$ & $\begin{array}{l}\text { Capillary tube } \\
\text { specification }\end{array}$ & $\begin{array}{l}\text { Capillary tube } \\
\text { length }(\mathrm{m})\end{array}$ & $\begin{array}{l}\text { Inner Diameter } \\
(\mathrm{mm})\end{array}$ & $\begin{array}{l}\text { Refrigerating } \\
\text { Effect }(\mathrm{W})\end{array}$ & COP \\
\hline 1 & SS & 3.600 & 0.78 & 217 & 2.20 \\
\hline
\end{tabular}

As per standard [11] the capillary tube parameters for R134a refrigerant having evaporator temperature $-10^{\circ} \mathrm{C}$, $1 / 6 \mathrm{hp}$ compressor is: capillary tube length $=3.600 \mathrm{~m}$ and diameter $=0.78 \mathrm{~mm}$. With this diameter and length of capillary tube, the results obtained are refrigerating effect $217 \mathrm{~W}$ and COP 2.20 .

Table III

Effect of Capillary tube size on various properties of R1234yf

\begin{tabular}{|l|l|l|l|l|l|}
\hline $\begin{array}{l}\text { Sr. } \\
\text { No. }\end{array}$ & $\begin{array}{l}\text { Capillary tube } \\
\text { specification }\end{array}$ & $\begin{array}{l}\text { Capillary tube } \\
\text { length }(\mathrm{m})\end{array}$ & $\begin{array}{l}\text { Inner Diameter } \\
(\mathrm{mm})\end{array}$ & $\begin{array}{l}\text { Refrigerating } \\
\text { Effect }(\mathrm{W})\end{array}$ & COP \\
\hline 1 & SS & 3.600 & 0.78 & 206 & 2.07 \\
\hline 2 & SM & 3.960 & 0.78 & 207 & 2.08 \\
\hline 3 & SL & 4.356 & 0.78 & 207 & 2.08 \\
\hline 4 & MS & 3.600 & 0.81 & 209 & 2.09 \\
\hline 5 & MM & 3.960 & 0.81 & 211 & 2.12 \\
\hline 6 & ML & 4.356 & 0.81 & 215 & 2.16 \\
\hline 7 & LS & 3.600 & 0.83 & 205 & 2.06 \\
\hline 8 & LM & 3.960 & 0.83 & 207 & 2.08 \\
\hline 9 & LL & 4.356 & 0.83 & 209 & 2.09 \\
\hline
\end{tabular}

For R1234yf, when the diameter of the capillary tube is kept constant and the capillary tube length is increased, the COP increases due to increase in refrigerating effect. The diameter of capillary tube was increased to 0.81 $\mathrm{mm}$ and $0.83 \mathrm{~mm}$ for R1234yf. This provided flexibility to the designer in selecting a capillary tube matching various parameters. Capillary tube ML for the refrigerant R1234yf with the internal diameter $0.81 \mathrm{~mm}$, length $4.360 \mathrm{~m}$ provides highest refrigerating effect: $215 \mathrm{~W}$ and COP: 2.16 .

It was revealed that for the same compressor work, the cooling capacity of R1234yf decreases, although R1234yf had about 25\% more saturation vapour density than R134a. However, this increase in saturation vapour density indicated by the R1234yf did not produce an equivalent increase in cooling capacity because the latent heat of vaporization of R1234yf was about $18 \%$ lower than that of the R134a, as shown in Table 4 [as per property table]. 
Table IV

Comparison of R134a and R1234yf properties at $-10.6^{\circ} \mathrm{C}$

\begin{tabular}{|l|l|l|l|}
\hline Property & R134a & R1234yf & {$[(\mathrm{R} 134 \mathrm{a}-\mathrm{R} 1234 \mathrm{yf}) /(\mathrm{R} 134 \mathrm{a})]^{*} 100$} \\
\hline $\begin{array}{l}\text { Sat. Vapour density } \\
\left(\mathrm{kg} / \mathrm{m}^{3}\right)\end{array}$ & 9.816 & 12.296 & -25.26 \\
\hline $\begin{array}{l}\text { Latent heat of } \\
\text { vapourization }(\mathrm{kJ} / \mathrm{kg})\end{array}$ & 206.40 & 169.81 & $+17.73 \%$ \\
\hline $\begin{array}{l}\text { Saturated pressure @ } \\
-10.6^{\circ} \mathrm{C}(\mathrm{kPa})\end{array}$ & 195.90 & 216.92 & -10.73 \\
\hline $\begin{array}{l}\text { Saturated pressure @ } \\
54.4^{\circ} \mathrm{C}(\mathrm{kPa})\end{array}$ & 1469.8 & 1444.5 & +1.72 \\
\hline
\end{tabular}

Over the range of operational conditions tested, the difference in terms of cooling capacity and COP is less than 5\% for R1234yf while the average difference between cooling capacity ( for SS) is $4.6 \%$ for R134a and R1234yf.The results are validated as per reference [12], the R1234yf system had 4.0-7.0\% smaller cooling capacity and $3.6-4.5 \%$ lower COP compared to the R134a system.

\section{CONCLUSION}

The following conclusions were drawn from this paper by optimizing capillary tube design parameters of system R1234yf as follows:

1. The analysis provides flexibility to the designer for selecting a capillary tube parameters for the environmentally friendly refrigerant R1234yf. In the present work, capillary tube ML for the refrigerant $\mathrm{R} 1234 \mathrm{yf}$ with the internal diameter $0.81 \mathrm{~mm}$, length $4.360 \mathrm{~m}$, provides the maximum refrigerating effect and the optimum value of the COP.

2. When the diameter of the capillary tube is kept constant and the capillary tube length is increased using R1234yf, COP increases due to increase in refrigerating effect.

3. As the diameter of capillary tube increases using R1234yf, mass flow rate increases with an increase in diameter of the capillary tube. It is evident that change in diameter on a percentage basis can change the flow more than an equal change in length.

4. Over the range of operational conditions tested, the maximum difference in terms of cooling capacity or COP is less than $5 \%$.

5. With the modifications in capillary tube parameters in this paper, R1234yf provides the substitute of R134a in terms of comparable COP.

\section{REFERENCES}

[1] Vijay Singh Bisht and A.K. Pratihar, "Thermodynamic analysis of actual vapour compression system with R12 and its eco- friendly alternatives refrigerants", International Journal of Engineering Research and Applications, Vol. 4, No. 4, pp. 114-122, 2014

[2] R. Saravanakumar and V. Selladurai, "Exergy analysis of a domestic refrigerator using eco-friendly R290/R600a refrigerant mixture as an alternative to R134a", Journal of Thermal Analysis and Calorimeter, Vol. 115, pp. 933-940, 2014.

[3] K. Mani and V. Selladurai, "Experimental analysis of a new refrigerant mixture as drop-in replacement for CFC12 and HFC134a", International Journal of Thermal Sciences, vol. 47, No.11, pp. 1490-1495, 2008.

[4] Pamela Reasor, Vikrant Aute and Reinhard Radermacher, "Refrigerant R1234yf performance comparison investigation", International Conference of Refrigeration and Air-Conditioning, Purdue University, 2010, paper 2300, pp. 1-7.

[5] M. Mohanraj, S. Jayaraj, C. Muraleedharan and P. Chandrasekar, "Experimental investigation of R290/R600a mixture as an alternative to R134a in a domestic refrigerator", International Journal of Thermal Sciences, Vol.49, No. 5, pp. 1036-1042, 2009.

[6] X.H. Han, Q. Wang, Z.W. Zhu and G.M. Chen, "Cycle performance study on R32/R125/R161 as an alternative refrigerant to R407C", Applied Thermal Engineering, Vol. 27, No. 14-15, pp. 2559-2565, 2007.

[7] Minxia Li, Chaobin Dang and Eiji Hihara, "Flow boiling heat transfer of HFO1234yf and R32 refrigerant mixtures in a smooth horizontal tube: Part I. Experimental investigation", International Journal of Heat and Mass Transfer, Vol. 55, No. 13-14, pp. $3437-$ $3446,2012$.

[8] Anant Agrawal, Avi A. Cornelio and Dirk, Limperich, "Investigation of cubic EOS models for HFO-1234yf refrigerant used in automotive application", International Conference of Refrigeration and Air-Conditioning, Purdue University, 2012, 2012, paper 2253, pp. 1-10.

[9] Kim Tiow Ooi, "Compressor performance comparison when using R134 and R1234yf as working fluids”, International Conference of Refrigeration and Air-Conditioning, Purdue University, 2012, paper 1113, pp. 1-5.

[10]Gaurav Jain and Clark Bullard, "Design and optimization of capillary tube-suction line heat exchangers", International Conference of Refrigeration and Air-Conditioning, Purdue University, 2004, paper R071, pp. 1-8.

[11] Application of Engineering Data, Copper Capillary Tubing for Refrigeration and Air-conditioning, J B Industries Aurora, IL60505, USA.

[12]Honghyun Cho and Chasik Park, "Experimental investigation of performance and exergy analysis of automotive air conditioning systems using refrigerant R1234yf at various compressor speeds", International Journal Applied Thermal Engineering, Vol. 101, pp. $30-37,2016$. 


\section{Author Biographies}

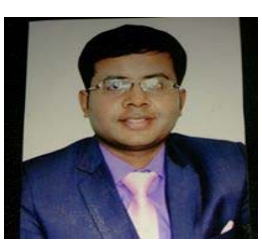

Mr. Gaurav is a research scholar in the Mechanical Engineering Department of YMCA University of Science and Technology, Faridabad, Haryana (India). He has completed his MTech in Thermal Engineering from NIT Kurukshetra, Haryana (India). He has a teaching experience of 6 Years.

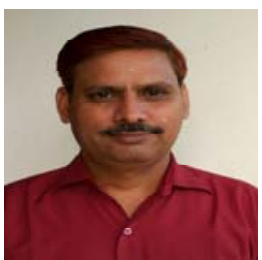

Dr. Raj Kumar is Professor in Mechanical Engineering Department of YMCA University of Science and Technology, Faridabad, Haryana (India). He has published several papers in reputed journals. He has guided many students at the level of UG and PG level. He has a teaching experience of more than 20 years. 